\title{
Biomasa residual pecuaria: revisión sobre la digestión anaerobia como método de producción de energía y otros subproductos
}

\section{Livestock residual biomass: review of anaerobic digestion as a method of energy production and other byproducts}

\section{David Leonardo Parra-Ortiz ${ }^{1}$, Mónica Andrea Botero-Londoño ${ }^{2}$, Julián Mauricio Botero-Londoño ${ }^{3}$}

\author{
${ }^{1}$ Suministros Eléctricos y Soluciones Tecnológicas S. A. S. Soltec-ING. Correo electrónico: \\ dalepaor@saber.uis.edu.co \\ ${ }^{2}$ Grupo de investigación Gisel, Escuela de Ingenierías Eléctrica, Electrónica y de Telecomunicaciones, Universidad \\ Industrial de Santander, Colombia. Correo electrónico: mabotero@saber.uis.edu.co \\ ${ }^{3}$ Grupo de investigación Gisel, Facultad de Zootecnia, Universidad Industrial de Santander, sede Málaga, Colombia. \\ Correo electrónico: ganaderiaagroforestal@gmail.com
}

Recibido: 3 marzo, 2018. Aceptado: 05 julio, 2018. Versión final: 27 agosto, 2018.

\begin{abstract}
Resumen
El biogás producido por la digestión anaerobia de residuos pecuarios es una solución para la sustitución de la biomasa tradicional usada en iluminación y calor. Su uso presenta ventajas como la mejora en la productividad de las fincas, la reducción del impacto ambiental y el rompimiento de la dependencia a los combustibles fósiles y agroquímicos. Sin embargo, aún se tiene poca difusión en las zonas rurales de Colombia, principalmente por el desconocimiento de las potencialidades y los beneficios. Por tal motivo, la presente revisión propone brindar una perspectiva de la digestión anaerobia desde los aspectos técnicos más relevantes, la importancia del sustrato y los tipos de biodigestores de bajo costo más comunes. Se concluye que es necesario mejorar las técnicas para hacerlas más asequibles y planear programas de financiación que permitan la expansión plena de la tecnología a pequeña y mediana escala.
\end{abstract}

Palabras clave: biogás; digestato; digestión anaerobia.

\begin{abstract}
The biogas produced by the anaerobic digestion of livestock waste is a solution for the replacement of traditional biomass used in lighting and heat. Its use offers advantages such as: the improvement in the productivity of the farms, reduction of the environmental impact and breaking the dependence on fossil fuels and agrochemicals. However, there is still little diffusion of it in rural areas of Colombia, mainly due to ignorance of its potential and benefits. For this reason, this review provides a perspective of anaerobic digestion from the most relevant technical aspects, the importance of the substrate and the most common types of low-cost biodigesters. It is concluded that it is necessary to improve the techniques to make them more affordable and to plan financing programs that allow the full expansion of this technology to small and medium scale.
\end{abstract}

Keywords: biogas; digestate; anaerobic digestion.

\section{Introducción}

La tendencia actual en cuanto al uso de la tierra para la ganadería extensiva en Colombia es la conversión de entornos naturales en pastos y rastrojos, que se extienden sobre tierras que son apropiadas para usos agrícolas, forestales e incluso sobre áreas protegidas y parques naturales. Como consecuencia de esto, se produce una

ISSN impreso: 1657 - 4583, ISSN en línea: 2145 - 8456, CC BY-ND 4.0 (c) (i) @

Como citar: D. Parra, M. Botero, J. Botero, "Biomasa residual pecuaria: revisión sobre la digestión anaerobia como método de producción de energía y otros subproductos," Rev. UIS Ing., vol. 18, no. 1, pp. 149-160, 2019. doi: 10.18273/revuin.v18n2-2019013 
subutilización e ineficiencia en el uso de los recursos con graves repercusiones ambientales [1]. A esta problemática se suma que, en los últimos años, el sector agropecuario ha presentado baja productividad y poca generación de empleos [2]-[4].

De acuerdo al Departamento Administrativo Nacional de Estadística (Dane), el área destinada para uso agropecuario en Colombia equivale a 43,0 millones de hectáreas y se distribuye en $80,0 \%$ para pastos y rastrojos, $19,7 \%$ para tierras de uso agrícola y $0,3 \%$ para infraestructura agropecuaria [5]. Esta marcada vocación ganadera ha sido responsable de la emisión de algunos de los gases con mayor potencial de calentamiento global (Global Warming Potential, GWP), con quivalentes en $\mathrm{CO}_{2}$ en el ámbito mundial. Entre esos gases se encuentran el metano $\left(\mathrm{CH}_{4}\right)$, proveniente de la fermentación entérica de rumiantes con 23 veces GWP; óxido nitroso $\left(\mathrm{NO}_{2}\right)$, proveniente del estiércol con 296 veces GWP y el amoniaco $\left(\mathrm{NH}_{3}\right)$, gran contribuyente a la acidificación de la lluvia y los ecosistemas [6], [7]. Como solución a esta problemática, algunos autores han propuesto controles de rápida adaptación y mitigación al calentamiento global, que incluyen la reducción de leña y su asociada deforestación, el mejoramiento de dietas animales a través de diversificación de insumos, la sustitución de agroquímicos y la migración hacia los sistemas silvopastoriles intensivos [8], [9]. Para tal efecto, la digestión anaerobia (DA) se presenta como una solución en la sustitución de la biomasa tradicional, no solo para satisfacer las necesidades básicas en iluminación, calor y electricidad, sino también para mejorar la productividad de las fincas, reducir el impacto ambiental por emisiones de gases y romper la dependencia a los combustibles fósiles y agroquímicos [10]. El uso de biogás, cuyo poder calorífico se asemeja al de muchos combustibles fósiles, puede mitigar en promedio un $85 \%$ de gases efecto invernadero emitidos en la producción de calor [11], [12]. Sin embargo, a pesar de sus beneficios, la DA aún tiene poca difusión en Colombia, principalmente por la insuficiente divulgación de aspectos técnicos, potencialidades y beneficios entre los productores agropecuarios. Por tal motivo, el presente artículo tiene como propósito realizar una revisión del estado del arte sobre la generación de energía y otros subproductos a partir de la biomasa residual de origen pecuario, considerando los aspectos técnicos más relevantes en la producción de biogás y digestato (bioabono); así como los impactos en el medioambiente, la sociedad y la economía.

\section{Aspectos técnicos en la producción de biogás}

\subsection{Proceso de digestión anaerobia (DA)}

El proceso de DA aprovecha el contenido bacteriano de la materia orgánica (sustrato) y en ausencia de aire se lleva a cabo un proceso de degradación cuyos productos finales son el digestato (efluente, biol o materia orgánica procesada) y el biogás (mezcla de varios gases, principalmente metano) [13].

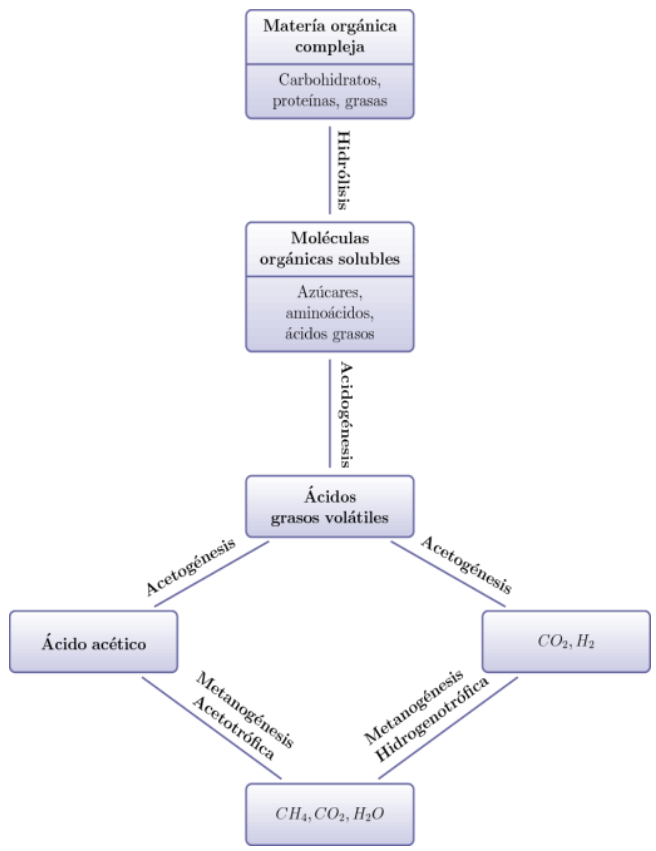

Figura 1. Proceso de digestión anaerobia. Fuente: adaptado de T. Abbasi, S. M. Tauseef, y S. A. Abbasi, Biogas Energy. 2012.

La DA se produce por cuatro diferentes cadenas tróficas a través de tres estados metabólicos consecutivos hidrólisis, acidogénesis y metanogénesis (figura 1). En primer lugar, la hidrólisis transforma, por medio de bacterias hidrolíticas, cadenas complejas de moléculas (p. ej. proteínas, carbohidratos y lípidos) en compuestos solubles (p. ej. aminoácidos, azúcares, alcoholes y en mayor proporción, cadenas largas de ácidos grasos). A continuación, el proceso de acidogénesis transforma los compuestos formados anteriormente en cadenas cortas de ácidos grasos volátiles (VFA, p. ej. ácido propiónico y butírico), ácido acético, hidrógeno $\left(\mathrm{H}_{2}\right)$ y dióxido de carbono $\left(\mathrm{CO}_{2}\right)$. Por último, bacterias metanogénicas convierten el ácido acético en $\mathrm{CH}_{4}$ y $\mathrm{CO}_{2}$ [13]. La materia remanente o digestato es rica en nutrientes, minerales ( $p$. ej. nitrógeno, fósforo, potasio, calcio, magnesio y sodio) y puede ser utilizada como fertilizante agrícola [13]-[15]. 


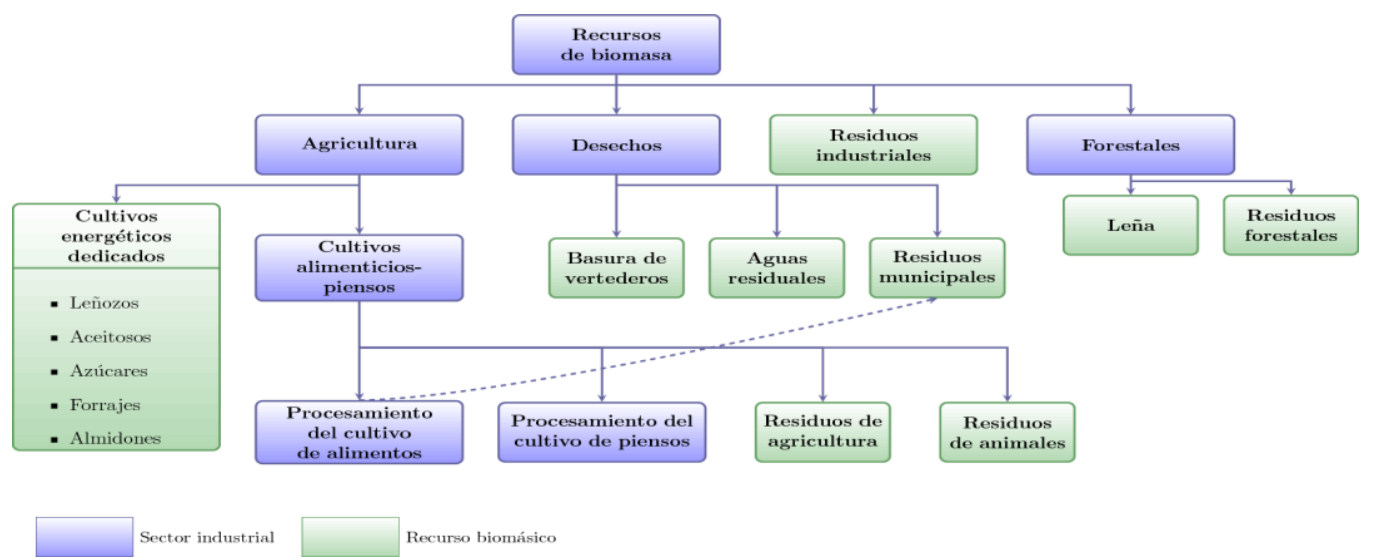

Figura 2. Fuentes principales de sustratos. Fuente: adaptado de F. Van Foreest, "Perspectives for biogas in Europe," 2012.

2.2. Fuentes de sustrato e influencia en la producción de biogás

Las principales fuentes de sustratos pueden provenir de cultivos y residuos agrícolas, aguas residuales, algas marinas, residuos sólidos municipales, estiércol y desechos animales, desechos biodegradables industriales, maleza, cultivos y residuos forestales, entre otros (figura 2) [13].

Las características del sustrato influyen en el diseño de los biodigestores. Por ejemplo, el contenido de materia seca, el potencial de acidificación y los riesgos patógenos determinan la forma de manejo del sustrato; la composición química y biológica determinan la clase de materiales de construcción que pueden soportar corrosión y la cantidad de sustrato disponible o de biogás requerido definen el potencial y las dimensiones del biodigestor [14]. El desafío actual en la DA es lograr un proceso eficiente, seguro y sostenible que maximice la utilización del sustrato a la vez que se obtengan las mejores características en los subproductos [16]. De esta manera, uno de los factores que más inciden en la eficiencia del proceso es el tipo, calidad y composición del sustrato medido principalmente por la relación carbono-nitrógeno $\mathrm{C} / \mathrm{N}$, el $\mathrm{pH}$ y el tamaño de partícula [17], [18]. La relación $\mathrm{C} / \mathrm{N}$ es la variable más significativa en el proceso de DA, esta expresa las proporciones relativas de carbono y nitrógeno en la materia orgánica, generalmente se utiliza un analizador elemental para su medición y se consideran valores óptimos los del rango 16:1 - 25:1 [19]. Un incremento excesivo del $\mathrm{C} / \mathrm{N}$ provoca un consumo rápido del nitrógeno por parte de las bacterias que, al tratar de suplir el déficit de proteína en el sustrato, reducen la producción de biogás. Por otra parte, una disminución excesiva del $\mathrm{C} / \mathrm{N}$ libera nitrógeno que se acumula en forma de amoniaco, lo que aumenta la acidez del pH y como consecuencia se crea un ambiente tóxico para las bacterias [19]. Un pH neutro es favorable para la producción de biogás y se considera óptimo el rango entre 6,7-7,5 [13], [18].

Una de las formas para optimizar el proceso de DA es aprovechar la influencia de la relación $\mathrm{C} / \mathrm{N}$ mediante la codigestión, que es la digestión simultánea de una mezcla de dos o más sustratos [19]. La codigestión puede incrementar la producción y la calidad del biogás y del digestato, acelerar el proceso de hidrólisis y, por lo tanto, reducir el tiempo promedio de permanencia del afluente dentro del biodigestor, factor conocido como el tiempo de retención hidráulica (HRT) [19]. Además, balancea la actividad bacteriana e inhibe la acumulación de VFA que provocan acidificación, de modo que se estabiliza la producción de biogás mediante la reducción de sulfuro de hidrógeno $\mathrm{H}_{2} \mathrm{~S}$ [19], [20].

Es usual que la codigestión se realice mediante la mezcla de estiércol animal (aporte de nitrógeno) en combinación con cultivos energéticos (aporte de carbono) como el sorgo, tallos de maíz, algodón o paja de trigo [21], [22]. Otros cosustratos con notables resultados en el laboratorio son los residuos de cocina (vegetales podridos), que demuestran ser una alternativa para incrementar el contenido de metano en el biogás y reducir los costos en los rellenos sanitarios [22].

Por último, la calidad del sustrato se puede mejorar variando el tamaño de las partículas mediante pretratamientos térmicos, químicos o termoquímicos y mecánicos [23].

\subsubsection{Pretratamiento térmico}

La aplicación de calor puede descomponer residuos orgánicos complejos en constituyentes más simples y biodegradables. Este proceso influye especialmente en la etapa de hidrólisis, que provoca su aceleración, reduce la 
cantidad de lodos e incrementa la producción de biogás [23], [24]. El proceso de DA es altamente sensible a los cambios bruscos de temperatura [25], por lo tanto, una vez definido el nivel de temperatura de operación, se debe procurar mantenerlo constante. Los diferentes niveles son psicrofílico $\left(<25^{\circ} \mathrm{C}\right)$, mesofílico $\left(25-45^{\circ} \mathrm{C}\right)$ y termofílico $\left(45-70{ }^{\circ} \mathrm{C}\right)$ [26]. La tabla 1 muestra una relación directa de la temperatura con el tiempo de retención hidráulico promedio.

Tabla 1. Relación del tiempo de retención hidráulica en función de la temperatura.

\begin{tabular}{ccc}
\hline Estado térmico & Temperatura de operación & Tiempo de retención mínimo \\
\hline Psicrofilico & $<20^{\circ} \mathrm{C}$ & $70-80$ días \\
Mesofilico & $30-42^{\circ} \mathrm{C}$ & $30-40$ días \\
Termofílico & $43-55^{\circ} \mathrm{C}$ & $15-20$ días \\
\hline
\end{tabular}

Fuente: adaptada de T. A. Seadi et al., Biogás Handbook, n. ${ }^{\circ}$ 1, 2008.

\subsubsection{Pretratamiento químico}

La finalidad del pretratamiento químico es mejorar la digestibilidad en sustratos de tipo lignocelulósicos (vegetales), los cuales están compuestos por celulosa, hemicelulosa y lignina [23]. La técnica consiste en adicionar químicos, generalmente hidróxido de sodio (soda cáustica) o hidróxido de calcio (cal apagada) para degradar el carbono del sustrato [24]; a este proceso también se le conoce como tratamiento alcalino y tiene efectos positivos en el incremento del contenido de $\mathrm{CH}_{4}$ [27]. El proceso se puede mejorar mediante la acción combinada de calor, lo que es conocido como pretratamiento termoquímico [28].

\subsubsection{Pretratamiento mecánico}

El pretratamiento mecánico consiste en reducir el tamaño de las partículas del sustrato y proporcionar un área de contacto mayor a las bacterias para la absorción del sustrato, por lo tanto, acelerar la producción de biogás [24]. El proceso se puede realizar utilizando molinos de bolas con agitación, rotura de chorro mecánico u homogeneizadores de alta presión [23]. Otra técnica con buenos resultados en climas fríos ha sido la adición de anillos de PET dentro del biodigestor como biofilminas portadoras, su función es la de incrementar la superficie de contacto entre las bacterias y el sustrato [29], [30], la principal ventaja de este tratamiento es la reducción del tiempo de digestión entre 23-59 \% comparado con procesos sin pretratamiento [23].

\subsection{Tipos de biodigestores anaerobios domésticos}

El diseño y la elección de un biodigestor depende de las condiciones climáticas de la zona, la composición y la cantidad disponible de los sustratos. Por ejemplo, un biodigestor instalado en zonas montañosas albergará el mínimo posible de biogás en su volumen, con el fin de evitar pérdidas; mientras que en zonas tropicales los biodigestores se instalan bajo tierra con el fin de aprovechar la energía geotérmica [18]. La figura 3 muestra los principales componentes de una planta de biogás, estos son (1) la zona de almacenamiento y pretratamiento de sustratos y digestato, (2) la unidad de digestión (biodigestor), (3) el tanque o dispositivo de almacenamiento del biogás, (4) los sistemas de transporte y aprovechamiento del biogás (incluyen válvulas, bombas y accesorios) y (5) los equipos de transformación en calor o electricidad. Existen tres tipos de biodigestores de bajo costo, que son los más comunes en las zonas rurales de Latinoamérica y en países en desarrollo. Estos biodigestores son los de domo fijo, de tambor flotante y tubulares plásticos [31], [32], que operan con estiércol animal y residuos de cosecha. Su volumen puede variar entre 5 y $20 \mathrm{~m}^{3}$ y proveen aproximadamente $0,5 \mathrm{~m}^{3} \mathrm{de}$ biogás por cada $1 \mathrm{~m}^{3}$ de biodigestor. El sustrato tiene un tiempo promedio de retención entre 20 y 30 días a temperatura mesofílica y el biogás tarda aproximadamente entre 40 y 45 días en Producirse dependiendo de las condiciones ambientales [13].

\subsubsection{Biodigestores de domo fijo y tambor flotante}

Los biodigestores de domo fijo y tambor flotante son construidos bajo tierra, con materiales como cemento, hierro, ladrillos y arena. El de tambor flotante tiene un tambor metálico que sobresale de la superficie de la tierra y modifica su posición de acuerdo al volumen producido de biogás. Este mantiene una presión constante en el biogás de acuerdo al peso ejercido del tambor o masas que se le adicionen. Por otra parte, el biodigestor de domo fijo mantiene el biogás a volumen constante en su propio interior mientras la presión varía a medida que se produce o libera el biogás [32].

Para la construcción de estos biodigestores, se requiere de mano de obra capacitada que evite al máximo las fugas de biogás y efluente. Adicionalmente, si se consideran las condiciones de transporte por carreteras inadecuadas, temporadas de lluvia, largas distancias, altos niveles de pobreza y la continua migración de la mano de obra rural a la ciudad, los costos globales de estos biodigestores no son adecuados para productores de bajos recursos [33]. El tiempo de vida de un biodigestor de domo fijo puede estar entre 15 y 20 años; mientras que un biodigestor de tambor flotante puede tener un tiempo de vida de entre 12 y 15 años, debido a la corrosión [34]. Ambos biodigestores no requieren sistemas de mezclado y operan sin control de temperatura. 


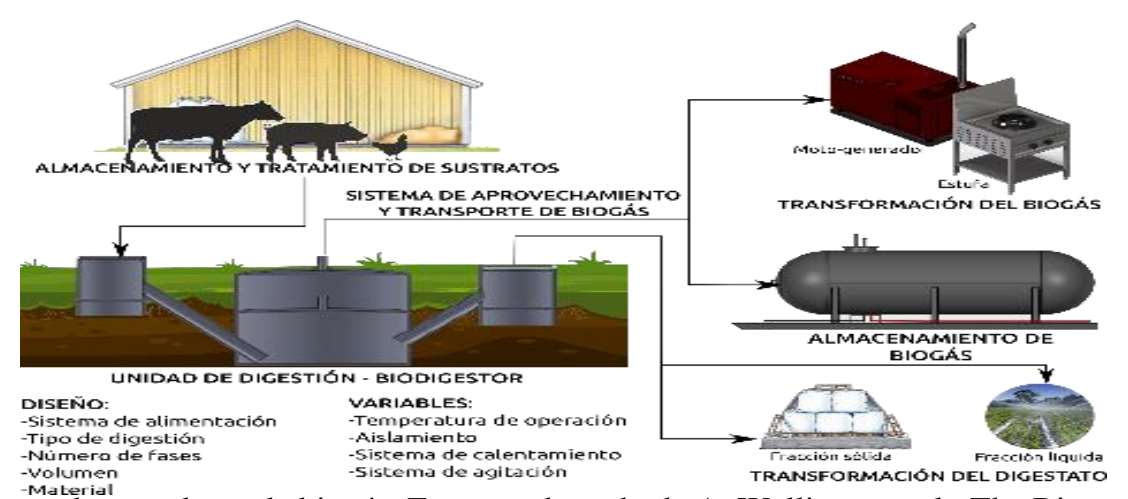

Figura 3. Partes de una planta de biogás. Fuente: adaptado de A. Wellinger et al., The Biogas Handbook:

Science, Production and Applications.

Su principal desventaja es la acumulación de sedimentos que reducen el volumen efectivo a lo largo del tiempo, por lo que se aconseja mantenimiento periódico de lavado en su interior [32].

\subsubsection{Biodigestor tubular}

Un biodigestor tubular consiste en dos mangas de plástico, polietileno o geomembrana concéntricos con tubos de entrada y salida en PVC de entre 4 y 6 pulgadas. El conjunto biodigestor es enterrado hasta la mitad con el fin de mantener la fase líquida dentro de una zanja previamente excavada. La fase gaseosa se forma en la parte superior del biodigestor y es extraída mediante tuberías directamente a la cocina o a tanques de almacenamiento. Se implementa una trampa de agua como válvula de alivio y opcionalmente un filtro con viruta de hierro entre el tanque de almacenamiento y la cocina para capturar el $\mathrm{H}_{2} \mathrm{~S}$ [33]. En lugares con temperaturas bajas el HRT se aumenta entre 60 y 90 días para permitir una correcta digestión del sustrato, en climas tropicales el HRT es menor y varía entre 20 y 60 días [35].

El biodigestor tubular se caracteriza por ser de muy bajo costo y operación simplificada, y, en comparación con los modelos de domo fijo y tambor flotante, su costo es aproximadamente la mitad del precio de ellos. Es ideal para comunidades rurales alejadas y con problemas de accesibilidad, ya que su transporte se puede realizar incluso a lomo de mula [33]. No requieren sistemas de mezclados o sistemas complejos de calentamiento. Generalmente se ubica en un invernadero para mantener la temperatura durante la noche. Su construcción y su mantenimiento no requieren mano de obra especializada [35]-[39]. Sin embargo, su principal desventaja es el tiempo de vida útil, el cual se estima entre 2 y 5 años para los de plástico. Materiales más elaborados como la geomembrana tienen tiempos de vida útiles hasta de 10 años [34].

\section{Biomasa residual en la generación de energía y otros subproductos}

La biomasa residual resuelve algunos de los problemas asociados al uso de cultivos energéticos exclusivos que generan conflictos entorno a la competencia y al cambio del uso de la tierra, la deforestación y la presión sobre cuerpos de agua [40]. Además, aporta soluciones al debate sobre el incremento del uso de la biomasa para energías renovables o el tránsito hacia una bioeconomía, basada en la diversificación de nuevos productos [41].

La DA es una solución que se puede obtener a partir de desechos, sin afectar el uso de la tierra y además permite una diversificación en la oferta de productos derivados que van desde el biogás per se y sus asociadas mejoras (biometano, syngas, Bio-LNG, etc.) hasta los digestatos como fuente de abonos orgánicos y minerales [42]. La figura 3 muestra los puntos de confluencia en los mercados en energías renovables y la bioeconomía.

\subsection{Potencial del uso del biogás en la generación de energía}

El uso de la energía para calor (agua o ambientes, cocina y procesos industriales) representó más del $50 \%$ del consumo total de energía en el mundo en el 2016 [43].

La participación de energías renovables para dicho propósito fue de cerca del $25 \%$, de cuya proporción dos tercios fue biomasa tradicional (leña) con uso predominante en países en vía de desarrollo y el tercio restante $(9 \%$ de la producción total de calor en el ámbito mundial) correspondió a formas modernas de energía renovables (bioenergía, solar-térmica y geotérmica) [43]. 


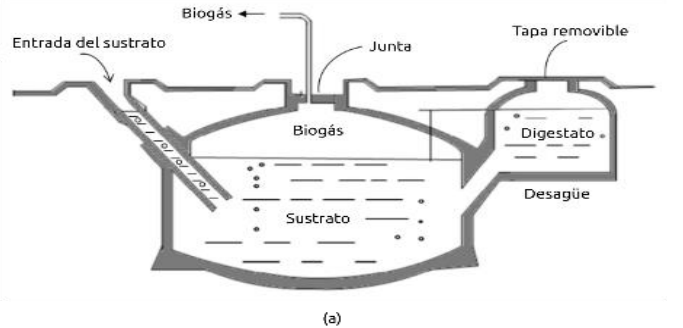

(a)

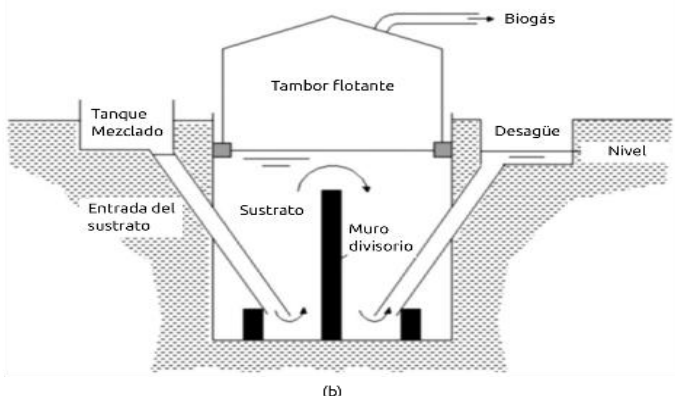

Figura 4. (a) Biodigestor de domo fijo, (b) biodigestor de tambor flotante. Fuente: adaptado de M. Garfí, J. et. al., "Household anaerobic digesters for biogas production in Latin America: A review".

La generación de electricidad proveniente de biomasa sólida y biogás tuvo un continuo crecimiento en 2016 en el ámbito mundial; Alemania, el mayor productor de electricidad a partir de biomasa en Europa, tuvo una capacidad instalada de generación de 52 TWh (187.200 TJ). Por otra parte, en Latinoamérica, Brasil tuvo una capacidad instalada de generación de 51 TWh (183.600 TJ) [43]. En Colombia, el potencial técnico de generación de energía, a partir de biomasa, excluyendo las fuentes que generan competencia en el uso y los combustibles líquidos (es decir, mediante digestión anaerobia), fue de $16.38 \mathrm{TWh}(58.984 \mathrm{TJ})$ [44]. Con base en el total de las fuentes el potencial energético aumenta a $30,13 \mathrm{TWh}$ $(108,472$ TJ) [45].

El biogás es considerado una forma versátil de energía puesto que se puede almacenar o distribuir a través de las redes de gas convencionales o exclusivas. Tal versatilidad le permite amortiguar las fluctuaciones de otras fuentes de energía como la fotovoltaica y la eólica [41], [46].

La tecnología de transformación del biogás en calor y energía (eléctrica o mecánica) es ampliamente conocida. El calor se puede producir mediante combustión directa en calderas o quemadores sin utilizar sistemas complejos de purificación. Para la producción de electricidad o torque mecánico, se utilizan motores o motogeneradores de combustión (Gas-Stirling, Gas-Otto, Gas-Diesel o inyección de Gas-piloto) o unidades de generación combinada de potencia y calor (CHPU); estos dispositivos requieren un biogás pretratado, drenado, seco y libre de trazas de sulfuro de hidrógeno, siloxanos $\mathrm{y}$ otros gases potenciales generadores de problemas de mantenimiento [26].

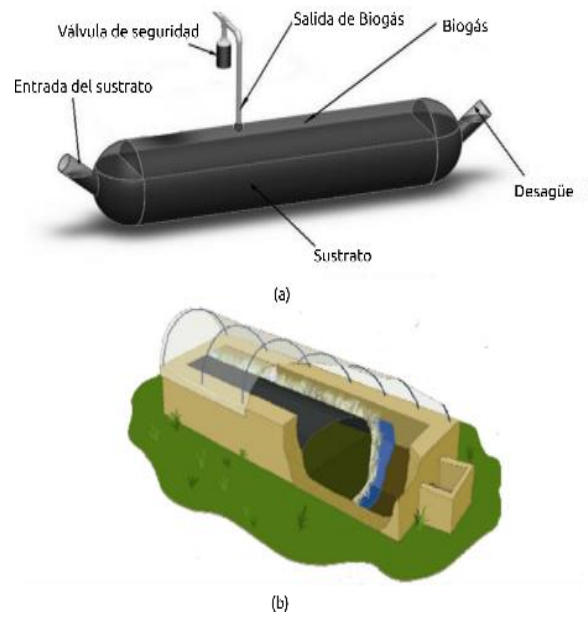

Figura 5. (a) Biodigestor tubular, (b) claustro; adaptación para climas fríos. Fuente: adaptado de M. Garfí, J. et al., "Household anaerobic digesters for biogas production in Latin America: A review".

\subsection{Potencial del uso del biogás en la extracción de subproductos derivados}

El biogás tiene una composición variable que depende mayormente del tipo de sustrato y las condiciones de operación del biodigestor; sin embargo, su contenido se puede estimar en metano $\left(50-70 \% \mathrm{CH}_{4}\right)$, dióxido de carbono (30-50\% $\mathrm{CO}_{2}$ ) y otros gases como vapor de agua, sulfuro de hidrógeno $\left(\mathrm{H}_{2} \mathrm{~S}\right)$ y amoníaco $\left(\mathrm{NH}_{3}\right)$ [32] De los mencionados gases, solamente el metano tiene la capacidad de suministrar energía, las demás trazas tienen características corrosivas o contaminantes, por lo que se deben reducir a través de procesos de purificación. La purificación busca eliminar las trazas de $\mathrm{H}_{2} \mathrm{~S}, \mathrm{NH}_{3}$ y siloxanos, y mejorar el biogás para darle nuevas características. A través de diversas técnicas se aumenta la concentración de metano, incluso a los mismos estándares que el gas natural (Biometano, Bio-LNG), de esta manera se puede inyectar a las redes de distribución $\mathrm{y}$ usarse en aplicaciones vehiculares [42]. Una comparación entre la composición del biogás crudo y el gas natural se puede observar en la tabla 2.

El mejoramiento del biogás crudo a biometano demanda porcentajes de más del $95 \%$ en $\mathrm{CH}_{4}$ con el remanente en $\mathrm{CO}_{2}$ [42]. Algunos estándares para el biometano se pueden observar en la tabla 3. 
Tabla 2. Comparación de la composición del biogás crudo y el gas natural.

\begin{tabular}{lcc}
\hline Componente & Biogás & Gas Natural \\
\hline Metano (\%) & $40-75$ & $87-97$ \\
Dióxido de carbono (\%) & $22-55$ & $0,1-1,0$ \\
Sulfuro de hidrógeno (ppm) & $50-5000$ & NA \\
Amoniaco (\%) & $0-1$ & NA \\
Agua (\%) (\%) & $0-10$ & NA \\
Nitrógeno (\%) & $0-5$ & $0,2-5,5$ \\
Oxigeno (\%) & $0-2$ & $0,01-0,1$ \\
Hidrógeno (\%) & $0-1$ & Traza $-0,02$ \\
\hline
\end{tabular}

Fuente: adaptado de: R. Kadam, et. al. "Recent advancement in biogas enrichment and its applications".

Tabla 3. Composición estándar para el biometano.

\begin{tabular}{lc}
\hline Característica & Requerimiento \\
\hline Metano $\mathrm{CH}_{4}(\%)$ & 90 \\
Humedad $\left(\mathrm{mg} / \mathrm{m}^{3}\right)$ & 16 \\
Sulfuro de hidrógeno $\mathrm{H}_{2} \mathrm{~S}\left(\mathrm{mg} / \mathrm{m}^{3}\right)$ & 30,3 \\
$\mathrm{CO}_{2}+\mathrm{N}_{2}+\mathrm{O}_{2}(\%)$ & 10 \\
Oxigeno $\mathrm{O}_{2}(\%)$ & 0,5 \\
\hline
\end{tabular}

Fuente: adaptado de R. Kadam, et al. "Recent advancement in biogas enrichment and its applications".

Otros productos como el gas de síntesis o syngas se pueden obtener a partir del biogás mediante el secado y auto reformado térmico que convierte el $\mathrm{CH}_{4}$ y $\mathrm{CO}_{2}$ en $\mathrm{H}_{2}$ y $\mathrm{CO}$ (Syngas). Este valioso producto es utilizado en la producción de combustibles líquidos, provee $\mathrm{H}_{2}$ para celdas de combustibles y mejora la combustión del biogás [42]. La cadena de valor del biogás es mostrada en la figura 6.

El desafío actual consiste en escalar las técnicas de purificación a nivel comercial; ya que hasta el momento solo se han probado a pequeña escala y a nivel de laboratorio. Así mismo, muchas técnicas de purificación requieren grandes cantidades de agua, que incluso con regeneración, representan un impacto ambiental muy alto; por lo tanto, el estudio actual se enfoca en la disminución en el uso de los recursos y el trabajo a niveles de presión más altos [42].

\subsection{Potencial del uso del digestato y subproductos derivados}

El efluente remanente de la DA, también conocido como digestato o biol, es un fertilizante mejorado en su contenido de macro y micronutrientes de fácil accesibilidad, rico en nitrógeno de amoniaco, fósforo y potasio, posee alta homogeneidad, reduce significativamente los olores y la germinación de maleza [47]. Dependiendo de sus propiedades, su uso se puede extender para mejorar o mantener las características físico-químicas de los suelos; para tal efecto, se prefiere un digestato con alto contenido de materia orgánica, carbón orgánico y nitrógeno orgánico [48].
La calidad del digestato depende fuertemente del tipo de sustrato, los pretratamientos y la codigestión [49]; esta última genera un incremento en el contenido de materia orgánica y balancea los nutrientes, de modo que produce efectos en los suelos como mejoras en el almacenamiento de nutrientes, capacidad de retención de humedad y estímulo de la actividad microbiana [50].

El digestato se valora a partir de su contenido declarado de nutrientes, $\mathrm{pH}$, homogeneidad, contenido de materia seca y orgánica. Estos parámetros deben ser determinados con el fin de evaluar la conveniencia de su aplicación, ya que la adición de materia orgánica de baja estabilización estimula en exceso la actividad microbiana, produce altos flujos de $\mathrm{CO}_{2}$ en el suelo, consumo de oxígeno, pérdidas de nitrógeno y un efecto de fitotoxicidad, lo que afecta el crecimiento de las plantas [48], [51].

El digestato se puede utilizar de manera directa o se puede refinar a través pretratamientos. El pretratamiento más conocido es la separación de fracciones líquidas y sólidas, utilizando los efectos de la gravedad o las máquinas centrifugas y separadores de prensa de tornillo [52]. La fracción sólida incrementa la estabilidad del suelo y el porcentaje de humedad; mientras que la fracción líquida se puede usar como reemplazo del agua potable en el riego de cultivos, lo que representa un beneficio para el ambiente [50]. A la fracción sólida también se le puede aplicar un proceso de secado para mejorar su transporte y su comercialización [52].

\section{Impactos asociados a la digestión anaerobia}

\subsection{Impactos ambientales}

La digestión anaerobia y el uso del biogás como combustible contribuyen ambientalmente a (1) reducir la emisión de gases efecto invernadero, (2) disminuir la deforestación ocasionada por el consumo de leña, (3) mejorar las condiciones de salud por reducción de humos contaminantes dentro de las cocinas y (4) reducir el impacto ocasionado por fertilizantes sintéticos en cuerpos de agua y suelos [33].

El uso de residuos animales y excretas humanas para la producción de biogás y digestatos en Latinoamérica mitiga alrededor de 316 millones de toneladas de $\mathrm{CO}_{2-}$ equ. al año [32], el biogás desplaza y reduce la dependencia a los combustibles fósiles no renovables y disminuye la producción de $\mathrm{CO}_{2}$ que no hace parte del ciclo normal del carbono [53]. La combustión del biogás se considera carbono neutral ya que el $\mathrm{CO}_{2}$ contenido y liberado es producido por mineralización natural; esto significa que ya ha sido retirado de la atmósfera por la 


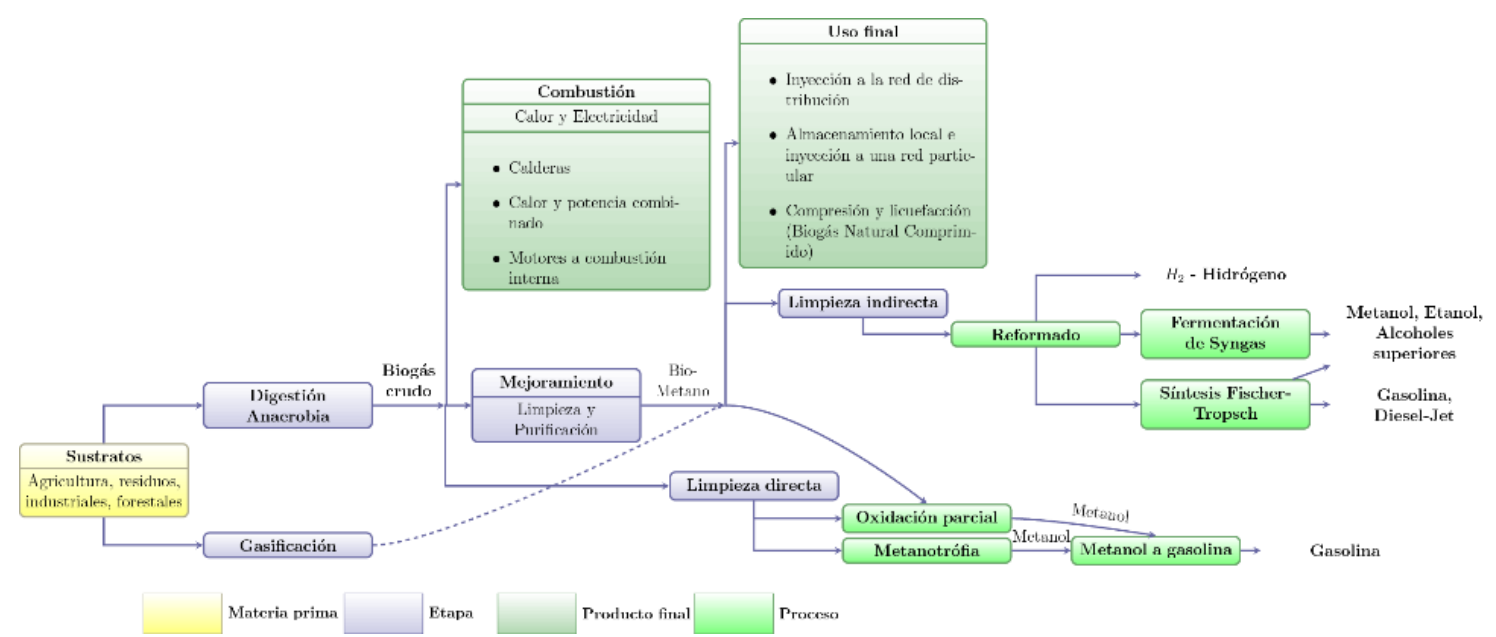

Figura 6. Cadena de valor del biogás. Fuente: adaptado de F. Van Foreest, "Perspectives for biogas in Europe," 2012.

absorción de las plantas utilizadas como sustrato y el alimento consumido por los animales, lo que complementa así el ciclo del carbono [26].

Como combustible limpio, ayuda a reducir la deforestación asociada al uso de la leña. Las estufas de biogás han reducido el consumo de leña y carbón a niveles entre el 66 y el $80 \%$ en el ámbito mundial, puesto que son más eficientes [43]. Algunos estudios estiman que el uso de biogás produce un ahorro de leña de 1.88 ton/año por familia [54] y hasta 3 ton/año en sistemas mejorados de DA [55].

Las estufas de biogás también han reducido enfermedades respiratorias, como infecciones agudas, bronquitis, asma, cáncer de pulmón, e infecciones de oído, causadas por la inhalación de humo dentro de las cocinas [56]. Las reducciones de humo reportadas están entre el 25-60,5 \% de acuerdo a la calidad de las estufas. Las poblaciones más favorecidas las constituyen mujeres y niños que permanecen mayor tiempo en la cocina [55].

En la agricultura, la aplicación de la fracción sólida del digestato puede reemplazar los fertilizantes sintéticos, y reducir notablemente el impacto ambiental por emisión de $\mathrm{CO}_{2}$ y $\mathrm{CH}_{4}$, provenientes de los procesos industrializados para su producción [50]. Así mismo, el manejo de los residuos ayuda a reducir la eutrofización (proliferación descontrolada de bacterias), producida por la aplicación excesiva y directa en el suelo o en cuerpos de agua de altos niveles de fosfato y nitrato contenidos en el estiércol [57]. Sin embargo, los beneficios ambientales dependen de cada una de las etapas en la cadena productiva del biogás y el digestato, y se deben cuidar para no ocasionar efectos adversos en el ambiente [16]. La obtención del sustrato puede ocasionar una huella de carbono debido a su transporte, por lo que es recomendable analizar las fuentes de sustratos locales y establecer los mecanismos adecuados para su recolección. En la producción y la operación de los biodigestores se encuentran asociados consumos de energía, materiales y recursos para los pretratamientos del sustrato, el biogás y el digestato [58], [59].

\subsection{Impactos sociales}

Se estima que cerca de 1,2 billones de personas (cerca del $16 \%$ de la población mundial) carecen del servicio de electricidad y que cerca de 2,7 billones de personas (38 $\%$ de la población global) carecen de tecnologías adecuadas para la cocción de alimentos. Esta cifra en Latinoamérica se acerca a los 65 millones de habitantes [43], y se sabe que en países como Haití existe alta dependencia de las formas tradicionales de biomasa como el carbón y la leña [60]. Los sistemas de producción de biogás son una de las formas de energía que más han aportado a la provisión de electricidad y calor a las comunidades más necesitadas. A finales del año 2015, se estimó que cerca de 700.000 biodigestores estuvieron en servicio en los países en vía de desarrollo [43]. Uno de los principales beneficios sociales para los habitantes rurales tiene que ver con la reducción del tiempo de recolección de biomasa sólida y la cocción de alimentos por parte de mujeres y niños, el tiempo ganado generalmente es invertido en el esparcimiento, el aprendizaje y el desarrollo de procesos productivos. Muchas mujeres invierten su tiempo en actividades comunitarias, lo que implica empoderamiento femenino en la sociedad [55]. De igual forma, como se mencionó anteriormente, el reemplazo de la biomasa sólida (madera, carbón, hojarasca o estiércol seco) como combustible por biogás genera ambientes más saludables libres de humo [61]. 


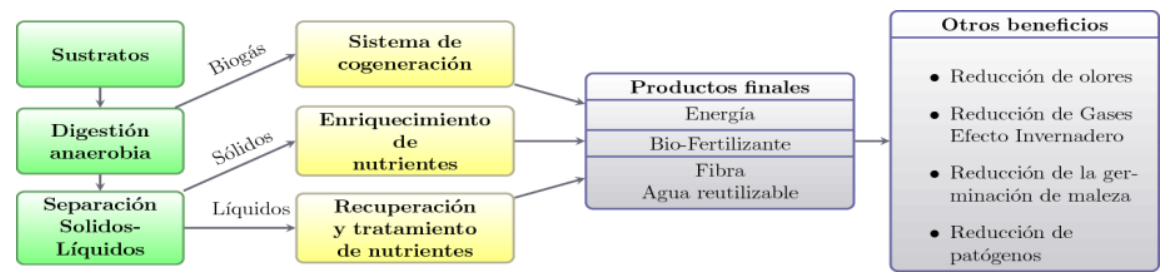

Figura 7. Beneficios directos e indirectos de la digestión anaerobia. Fuente: adaptado de E. K. Yiridoe - "Non Market cobenefits and economic feasibility of on-farm biogas energy production".

\subsection{Impactos económicos}

En comunidades rurales de escasos recursos y con problemas de accesibilidad, los biodigestores tubulares de plástico son la alternativa más económica. Los costos por materiales de un biodigestor tubular de plástico pueden estar dentro del rango de los 220-280 USD [33], mientras que los de polietileno de alta calidad, PVC o geomembrana podrían costar entre 500 y 700 USD y los de domo fijo o tambor flotante podrían costar entre $700 \mathrm{y}$ 1.200 USD [31]. En la producción de calor para la cocción de alimentos, el biogás tiene un costo específico de 0,17 USD/persona/día, el más bajo frente a otras fuentes como la biomasa sólida (leña) con un costo de 0,5 USD/persona/día, el gas (LPG) de 0,43 USD/persona/día y la electricidad con un costo de 1,03 USD/persona/día [43].

En cuanto a la generación de empleo, la producción de biogás requiere de mano de obra para la producción, recolección y transporte de los sustratos, fabricación de equipos técnicos, construcción, operación y mantenimiento. De esta manera, se generan empleos directos e indirectos que incrementan los ingresos en las zonas rurales [26]. La producción del efluente digestato (también conocido como Biol), y su utilización y comercialización como fertilizante orgánico, ha mostrado un gran potencial en la mejora de cultivos, y, por lo tanto, en los ingresos de los productores, este subproducto aumenta la sostenibilidad económica de los productores pequeños, debido a la reducción de costos por fertilizantes [50]. Además de los ingresos producidos por el biogás y el digestato, existen beneficios asociados que contribuyen económica y ambientalmente de manera indirecta. Por ejemplo, la reducción de olores, la mejora en las cosechas y la reducción de maleza, la reducción de patógenos, la recuperación del contenido de agua en los sustratos y la reducción de gases efecto invernadero. Estos beneficios asociados generan nuevas e importantes perspectivas sobre la viabilidad de invertir en biogás, y, por lo tanto, se deben tener en cuenta en los análisis financieros [62]. La figura 7 muestra los beneficios directos e indirectos asociados a la producción de biogás.

\section{Conclusiones y recomendaciones}

Se pudo evidenciar que la digestión anaerobia es un proceso ampliamente estudiado por la comunidad científica. Sin embargo, aún perduran limitaciones de tipo técnico, capacitación, divulgación y programas de financiación que impiden la expansión plena de la tecnología a pequeña y mediana escala. No obstante, con los medios disponibles, los productores rurales pueden llevar a cabo acciones a su alcance para mejorar los procesos de digestión anaerobia desde el uso de sustratos, operación de los biodigestores, uso y tratamiento de biogás y digestato, y en general aprovechar las bondades económicas, sociales y ambientales de esta tecnología. En cuanto a los sustratos, las recientes investigaciones demuestran que la apropiada selección de materias primas, según sus facilidades de obtención, su calidad y la condición de que no generen conflictos de intereses con otros usos, es la clave para diversificar la participación de la población rural en los mercados de las energías renovables y la bioeconomía. Se hace necesario continuar y ampliar las investigaciones referentes a la codigestión que permitan desplegar todas las posibilidades y potencialidades de materias primas al alcance de los productores rurales. De igual forma, y con el fin de contribuir a la mitigación y la adaptación al cambio climático en las zonas rurales, se requiere estudiar la influencia de la diversificación de insumos en la alimentación animal y en la producción de biogás. Respecto al uso de biodigestores, se evidenció que el éxito de su mantenimiento y su operación depende fuertemente de la motivación del productor; por tal motivo, es necesario que las personas se involucren en todas las etapas de evaluación, adquisición e instalación de los equipos; así mismo, se hace necesario que reconozcan sus bondades y potencialidades. Para tal propósito, los biodigestores tubulares de plástico, por su bajo costo, son la mejor opción para la experimentación y la capacitación de los productores rurales.

En conclusión, la digestión anaerobia, por sus beneficios sociales, ambientales y económicos, contribuye a la mitigación y la adaptación al cambio climático de las zonas rurales. 


\section{Referencias}

[1] M. A. Mora Marín, L. Ríos Pescador, L. Ríos Ramos, y J. L. Almario Charry, "Impacto de la actividad ganadera sobre el suelo en Colombia", Ing. y Región, vol. 17, pp. 1, 2017. doi: 10.25054/22161325.1212

[2] W. Vergara Vergara, "La ganadería extensiva y el problema agrario. El reto de un modelo de desarrollo rural sustentable para Colombia", Rev. Cienc. Anim., no. 3, pp. 45-53, 2010.

[3] A. Acosta, "Cambio climático y desarrollo pecuario: desafíos institucionales para el desarrollo sostenible de sistemas silvopastoriles en centroamérica", en VI Congreso Latinoamericano de Agroforestería para la Producción Pecuaria Sostenible, Panamá. CATIE: Turrialba, Costa Rica, 2010.

[4] L. Mahecha, L. A. Gallego, y F. J. Peláez, "Situación actual de la ganadería de carne en Colombia y alternativas para impulsar su competitividad y sostenibilidad", Rev. Colomb. Ciencias Pecu., vol. 15, no. 2, pp. 213-225, 2002.

[5] DANE, "Tercer Censo Nacional Agropecuario: Uso, cobertura y tenencia del suelo", 2016.

[6] M. Peters et al., "Challenges and opportunities for improving eco-efficiency of tropical forage-based systems to mitigate greenhouse gas emissions," Trop. Grasslands-Forrajes Trop., vol. 1, no. 2, pp. 156-167, 2013.

[7] H. Steinfeld, P. Gerber, T. Wassenaar, V. Castel, M. Rosales, y C. De Haan, Livestock's Long Shadow. Roma: Food and Agriculture Organization of The United Nations, 2006.

[8] E. Murgueitio, R. Barahona, J. D. Chará, M. X. Flores, R. M. Mauricio, y J. J. Molina, "The intensive silvopastoral systems in Latin America sustainable alternative to face climatic change in animal husbandry," Cuba. J. Agricultural Sci., vol. 49, no. 4, pp. 541-554, 2015.

[9] M. Montagnini, "Restoration of degraded pastures using agrosilvopastoral systems with native trees in the neotropics," Agroforestry as a Tool for Landscape Restoration, 2011, pp. 55-68.

[10] N. Sharma, B. Bohra, N. Pragya, R. Ciannella, P. Dobie, y S. Lehmann, "Bioenergy from agroforestry can lead to improved food security, climate change, soil quality, and rural development,",Food Energy Secur., vol. 5, no. 3, pp. 165-183, 2016. doi: 10.1002/fes3.87

[11] OECD, Bioheat, Biopower and Biogas. 2010. doi: 10.1787/9789264085862-en

[12] S. Bringezu, H. Schütz, M. O’Brien, L. Kauppi, R. W. Howarth, y J. McNeely, Towards sustainable production and use of resources: assessing biofuels. Chatelaine: United Nations Environment Programme (UNEP), 2009.

[13] T. Abbasi, S. M. Tauseef, y S. A. Abbasi, Biogas Energy. 2012.

[14] A. Wellinger, J. Murphy, y D. Baxter, The Biogas Handbook: Science, Production and Applications. 2013.

[15] M. M. T. Varnero, "Manual de biogás. Gobierno de Chile. Programa de las Naciones Unidas para el Desarrollo, Organización de las Naciones Unidas para la Alimentación y la Agricultura. Global Environment Facility," Proyecto CHI/00, 2011.

[16] S. Ruile, S. Schmitz, M. Mönch-Tegeder, y H. Oechsner, "Degradation efficiency of agricultural biogas plants - A full-scale study," Bioresour. Technol., vol. 178, pp. 341-349, 2015. doi: 10.1016/j.biortech.2014.10.053

[17] L. Naik, Z. Gebreegziabher, V. Tumwesige, B. B. Balana, J. Mwirigi, y G. Austin, "Factors determining the stability and productivity of small scale anaerobic digesters," Biomass and Bioenergy, vol. 70, pp. 51-57, 2014. doi: 10.1016/j.biombioe.2014.01.055

[18] K. Rajendran, S. Aslanzadeh, y M. J. Taherzadeh, "Household biogas digesters-A review," Energies, vol. 5, no. 8, pp. 2911-2942, 2012. doi: 10.3390/en5082911

[19] Z. Zhang, G. Zhang, W. Li, C. Li, y G. Xu, "Enhanced biogas production from sorghum stem by codigestion with cow manure," Int. J. Hydrogen Energy, vol. 41, no. 21, pp. 9153-9158, 2016. doi: 10.1016/j.ijhydene.2016.02.042

[20] S. Zareei y J. Khodaei, "Modeling and optimization of biogas production from cow manure and maize straw using an adaptive neuro-fuzzy inference system," Renew. Energy, vol. 114, pp. 423-427, 2017. doi: 10.1016/j.renene.2017.07.050

[21] L. Lijó, Y. Lorenzo-Toja, S. González-García, J. Bacenetti, M. Negri, y M. T. Moreira, "Eco-efficiency assessment of farm-scaled biogas plants," Bioresour. 
Technol., vol. 237, pp. 146-155, 2017. doi: 10.1016/j.biortech.2017.01.055

[22] F. Tasnim, S. A. Iqbal, y A. R. Chowdhury, "Biogas production from anaerobic co-digestion of cow manure with kitchen waste and Water Hyacinth," Renew. Energy, vol. 109, pp. 434-439, 2017. doi: 10.1016/j.renene.2017.03.044

[23] S. Fang, L. Ping, Z. Yang, y J. Mao, "A review of different pretreatment techniques for enhancing biogas production," 2011 International Conference on Materials for Renewable Energy \& Environment, Shanghai, 2011, pp. 263-266. doi: 10.1109/ICMREE.2011.5930810

[24] W. Uddin et al., "Biogas potential for electric power generation in Pakistan: A survey," Renew. Sustain. Energy Rev., vol. 54, pp. 25-33, 2016. doi: 10.1016/j.rser.2015.09.083

[25] T. Perrigault, V. Weatherford, J. Martí-Herrero, y D. Poggio, "Towards thermal design optimization of tubular digesters in cold climates: A heat transfer model," Bioresour. Technol., vol. 124, pp. 259-268, 2012. doi: 10.1016/j.biortech.2012.08.019

[26] T.A. Seadi, D. Rutz, H. Prassl, et al., Biogas Handbook. Esbjerg, Denmark: University of Southern Denmark Esbjerg, 2008.

[27] F. Monlau, P. Kaparaju, E. Trably, J. P. Steyer, y H. Carrere, "Alkaline pretreatment to enhance one-stage $\mathrm{CH} 4$ and two-stage $\mathrm{H} 2 / \mathrm{CH} 4$ production from sunflower stalks: Mass, energy and economical balances," Chem. Eng. J., vol. 260, pp. 377-385, 2015. doi: 10.1016/j.cej.2014.08.108

[28] H. Wang y H.-T. Wang, "Digestibility improvement of aspen leaf with alkaline hydrothermal pretreatment," Zhongguo Huanjing Kexue/China Environ. Sci., vol. 29, no. 2, 2009.

[29] Y. Liu et al., "Effects of different biofilm carriers on biogas production during anaerobic digestion of corn straw," Bioresour. Technol., vol. 244, no. 30, pp. 445451, 2017. doi: 10.1016/j.biortech.2017.07.171

[30] J. Martí-Herrero, R. Alvarez, M. R. Rojas, L. Aliaga, R. Céspedes, y J. Carbonell, "Improvement through low cost biofilm carrier in anaerobic tubular digestion in cold climate regions," Bioresour. Technol., vol. 167, pp. 8793, 2014. doi: 10.1016/j.biortech.2014.05.115
[31] M. Garfí, J. Martí-Herrero, A. Garwood, y I. Ferrer, "Household anaerobic digesters for biogas production in Latin America: A review," Renew. Sustain. Energy Rev., vol. 60, pp. 599-614, 2016. doi: 10.1016/j.rser.2016.01.071

[32] K. C. Surendra, D. Takara, A. G. Hashimoto, y S. K. Khanal, "Biogas as a sustainable energy source for developing countries: Opportunities and challenges," Renew. Sustain. Energy Rev., vol. 31, pp. 846-859, 2014.

[33] J. Martí-Herrero et al., "Low cost tubular digesters as appropriate technology for widespread application: Results and lessons learned from Bolivia," Renew. Energy, vol. 71, pp. 156-165, 2014. doi: 10.1016/j.renene.2014.05.036

[34] A. Yasar, S. Nazir, R. Rasheed, A. B. Tabinda, y M. Nazar, "Economic review of different designs of biogas plants at household level in Pakistan," Renew. Sustain. Energy Rev., vol. 74, pp. 221-229, 2017. doi: $10.1016 /$ j.rser.2017.01.128

[35] I. Ferrer, M. Garfí, E. Uggetti, L. Ferrer-Martí, A. Calderón, y E. Velo, "Biogas production in low-cost household digesters at the Peruvian Andes," Biomass and Bioenergy, vol. 35, no. 5, pp. 1668-1674, 2011.

[36] I. Ferrer, M. Gamiz, M. Almeida, y A. Ruiz, "Pilot project of biogas production from pig manure and urine mixture at ambient temperature in Ventanilla (Lima, Peru)," Waste Manag., vol. 29, pp. 168-173, 2009.

[37] M. Garfí, P. Gelman, J. Comas, W. Carrasco, y I. Ferrer, "Agricultural reuse of the digestate from low-cost tubular digesters in rural Andean communities," Waste Manag., vol. 31, pp. 2584-2589, 2011.

[38] H. Bouallagui, R. Ben Cheikh, L. Marouani, y M. Hamdi, "Mesophilic biogas production from fruit and vegetable waste in a tubular digester," Bioresour. Technol., vol. 86, pp. 85-89, 2003.

[39] S. Lansing, R. B. Botero, y J. F. Martin, "Waste treatment and biogas quality in small-scale agricultural digesters," Bioresour. Technol., vol. 99, pp. 5881-5890, 2008.

[40] M. A. Gonzalez-Salazar et al., "Methodology for biomass energy potential estimation: Projections of future potential in Colombia," Renew. Energy, vol. 69, pp. 488-505, 2014.

[41] S. F. Pfau, J. E. Hagens, y B. Dankbaar, "Biogas between renewable energy and bio-economy policies- 
opportunities and constraints resulting from a dual role," Energy. Sustain. Soc., vol. 7, no. 1, 2017.

[42] R. Kadam y N. L. Panwar, "Recent advancement in biogas enrichment and its applications", Renew. Sustain. Energy Rev., vol. 73, pp. 892-903, 2017.

[43] REN21, Renewables 2017 Global Status Report. Paris: REN21Secretariat, 2017.

[44] M. A. Gonzalez-Salazar et al., "Methodology for estimating biomass energy potential and its application to Colombia," Appl. Energy, vol. 136, pp. 781-796, 2014.

[45] UPME, "Balance Energético Colombiano - BECO”, Balance Energético Colombiano - BECO 1975 -2015, 2015. [En línea]. Disponible en: http://www1.upme.gov.co/InformacionCifras/Paginas/B ECOCONSULTA.aspx. [Accedido: 10-abr-2018].

[46] B. K. Das, N. Hoque, S. Mandal, T. K. Pal, y M. A. Raihan, "A techno-economic feasibility of a stand-alone hybrid power generation for remote area application in Bangladesh," Energy, vol. 134, pp. 775-788, 2017. Doi: 10.1016/j.energy.2017.06.024

[47] C. Teglia, A. Tremier, y J. L. Martel, "Characterization of solid digestates: Part 2, assessment of the quality and suitability for composting of six digested products," Waste and Biomass Valorization, vol. 2, no. 2, pp. 113-126, 2011.

[48] R. Nkoa, "Agricultural benefits and environmental risks of soil fertilization with anaerobic digestates: A review," Agron. Sustain. Dev., vol. 34, no. 2, pp. 473492, 2014. doi: 10.1007/s13593-013-0196-z

[49] J. A. Alburquerque et al., "Assessment of the fertiliser potential of digestates from farm and agroindustrial residues," Biomass and Bioenergy, vol. 40, pp. 181-189, 2012.

[50] A. Muscolo, G. Settineri, T. Papalia, E. Attinà, C. Basile, y M. R. Panuccio, "Anaerobic co-digestion of recalcitrant agricultural wastes: Characterizing of biochemical parameters of digestate and its impacts on soil ecosystem," Sci. Total Environ., vol. 586, pp. 746752, 2017. doi: 10.1016/j.scitotenv.2017.02.051

[51] M. Solé-Bundó et al., "Assessing the agricultural reuse of the digestate from microalgae anaerobic digestion and co-digestion with sewage sludge," Sci. Total Environ., vol. 586, pp. 1-9, 2017.
[52] A. Wellinger, J. Murphy, D. Baxter, A. Welliger, J. Murphy, y D. Baxter, The Biogas Handbook: Science, Production and Applications, 1 ra. Cambridge, UK.: Woodhead Publishing Limited, 2013.

[53] A. J. Ward, P. J. Hobbs, P. J. Holliman, y D. L. Jones, "Optimisation of the anaerobic digestion of agricultural resources," Bioresour. Technol., vol. 99, no. 17, pp. 7928-7940, 2008.

[54] M. Garfí, L. Ferrer-Martí, E. Velo, y I. Ferrer, "Evaluating benefits of low-cost household digesters for rural Andean communities," Renew. Sustain. Energy Rev., vol. 16, no. 1, pp. 575-581, 2012.

[55] H. Katuwal y A. K. Bohara, "Biogas: A promising renewable technology and its impact on rural households in Nepal," Renew. Sustain. Energy Rev., vol. 13, no. 9, pp. 2668-2674, 2009.

[56] N. Bruce, R. Perez-Padilla, y R. Albalak, "Indoor air pollution in developing countries: a major environmental and public health challenge," Environ. Heal., vol. 78, no. 9 , pp. $15,2000$.

[57] G. Kaur, Y. S. Brar, y D. P. Kothari, "Potential of livestock generated biomass: Untapped energy source in India," Energies, vol. 10, no. 7, pp. 1-15, 2017. doi: 10.3390/en 10070847

[58] M. Poeschl, S. Ward, y P. Owende, "Environmental impacts of biogas deployment - Part I: Life Cycle Inventory for evaluation of production process emissions to air," J. Clean. Prod., vol. 24, pp. 168-183, 2012.

[59] M. Poeschl, S. Ward, y P. Owende, "Environmental impacts of biogas deployment - Part II: Life Cycle Assessment of multiple production and utilization pathways," J. Clean. Prod., vol. 24, pp. 184-201, 2012.

[60] S. Lansing, A. Maile-Moskowitz, y A. Eaton, "Waste treatment and energy production from smallscale wastewater digesters," Bioresour. Technol., vol. 245, pp. 801-809, 2017. doi: 10.1016/j.biortech.2017.08.215

[61] A. Visser y H. R. Khan, "When smoke gets in your eyes: kitchen air quality in rural Bangladeshi homes," Energy for Sustainable Development, vol. 3, no. 4, pp. 52-57, 1996.

[62] E. K. Yiridoe, R. Gordon, y B. B. Brown, "Non Market cobenefits and economic feasibility of on-farm biogas energy production," Energy Policy, vol. 37, no. 3, pp. 1170-1179, 2009. doi: 10.1016/j.enpol.2008.11.018 